\title{
Quantitative Measuring Model and Variable Speed-limit Technology of Complicated Traffic Environment of Freeway
}

\author{
WU Yang*, YUAN Jianhua, LI Biao \\ Traffic Management Research Institute of Ministry of Public Security, Wuxi Jiangsu, 214151
}

\begin{abstract}
Variable speed-limit for complicated traffic environment of freeway lacks quantitative rules and decision -making technology. This paper establishes comprehensive quantitative measuring \& evaluating model, depending on the values of 7-factor indices (including: visibility, wind force, rainfall/snowfall, pavement icing/snow thickness, traffic level of service), employing the relation model of traffic 'flowratedensity-velocity' and the calculating model of vehicle's stopping-sight-distance \& critical-skiddingequilibrium, incorporated with authentic technical standards, based on single-factor fuzzy measuring \& evaluation, executes multi-factor comprehensive measuring \& evaluation on the reasonable limiting-speeds subject to given complicated traffic environment, so as to present the quantitative rules and tactics of the variable speed-limit of freeway.

KEYWORD: Complicated Traffic Environment of Freeway; Quantitative Single/Multi-factor Measuring \& Evaluating; Quantitative Rules for Variable Speed-limit; Flowrate-density-velocity Relation Model of Traffic Flow; Stopping Sight Distance; Sliding/Skidding.
\end{abstract}

\section{INDUCTION}

Complicated traffic environment elements (including: Fog, Haze, Sandstorm, Rain, Snow, Icing, Congestion, etc) endangering traffic safety of freeway, entail temporary speed-limit. Over/under-estimated limiting speeds cause unnecessary efficiency loss or under- lying safety hazard. Thus, quantitative measuring \& evaluating model and variable speed-limit techno-logy for complicated traffic environment of freeway are in urgent needs to executes multi-factor compre- hensive measuring \& evaluation on the reasonable limiting-speeds subject to given complicated traffic environment.

\section{LITERATURE REVIEW}

The existing relevant literatures on the speed-limit of freeway are categorized as follows: (1) Comprehensive safety evaluation for traffic environment, represented bytechnical standards [3,4], evaluates multiple environmental factors (and their quantitative indicators) by a certain gauge, mostly outputting qualitative safety-grades or comparisons which are basically disassociated from quantitative limiting-speed, lacks quantitativeness; Quantitative analyses on the limiting-speed under different environmental circumstances, represented by literatures $[5,6]$, mostly limited to single factor (such as Rainfall or Fog), lacks the comprehensiveness of multiple factors (especially the congestion factor); (3) Comprehensivequantitative studies guided by statistical data-mining, represented by HDM-III[7], HSM[8], acquire the driving-speed statistic subject to multi-factor impacts, in the nature of the Approxima- tion/Fitting of the Statistically Central values of safe speeds (without accidents) of dangerous speeds (accident-triggering), not being the Critical Thresholds between the two types of speeds (Note: Limiting speeds equal just critical thresholds), thus restricted eventually.

The reasonable limiting speed need to be analyzed in both comprehensive and quantitative ways, releying on model-driven methodology more than data-driven one. Moreover, expert experience need to be restrained with prudence, avoiding subjective bias.

\section{QUANTITATIVE SINGLE-FACTOR} MEASURING \& EVALUATING MODEL OF COMPLICATED TRAFFIC ENVIRONMENT AND SPEED-LIMIT TACTICS

The key to quantitative single-factor measuring \& evaluation (model) is how to establish the 
quantitative mapping rules of limiting speeds subject to the indicators' values of environmental factors. For sake of the feasibility of later comprehensive multi-factor evaluation by a certain gauge on multi-indicator with different dimensionalities, 6 safety-grades need to be introduced (into the model) equivalently bound with 6 graded limiting speeds respectively, as Fig.3-1-a, so as to enable both the quantitative analysis and the comprehensive evaluation.

In view of the observability, 7 factors are employed (Visibility, Wind velocity, Rainfall, Snowfall, Pavement Ice, Pavement Snow, Ratio of Volume to Capacity), with the quantitative indicators $\left\{x_{i} \mid i=1, \ldots, 7\right\}$, where the $V / C$ ratio implies 4 types of traffic-flow density[1] corresponding to 4 classes of Level of Service (LOS) of freeway. According to the grade differential of 10 or $20 \mathrm{~km} / \mathrm{h}$ of design speed for freeway[1], limiting speeds is set to 6 grades: Lane-shutdown, $\leq 20 \mathrm{~km} / \mathrm{h}, \leq 40 \mathrm{~km} / \mathrm{h}$, $\leq 60 \mathrm{~km} / \mathrm{h}, \leq 80 \mathrm{~km} / \mathrm{h}$, Legal-limit (e.g. design speed or $85 \%$ percentile of practical speed [14]).

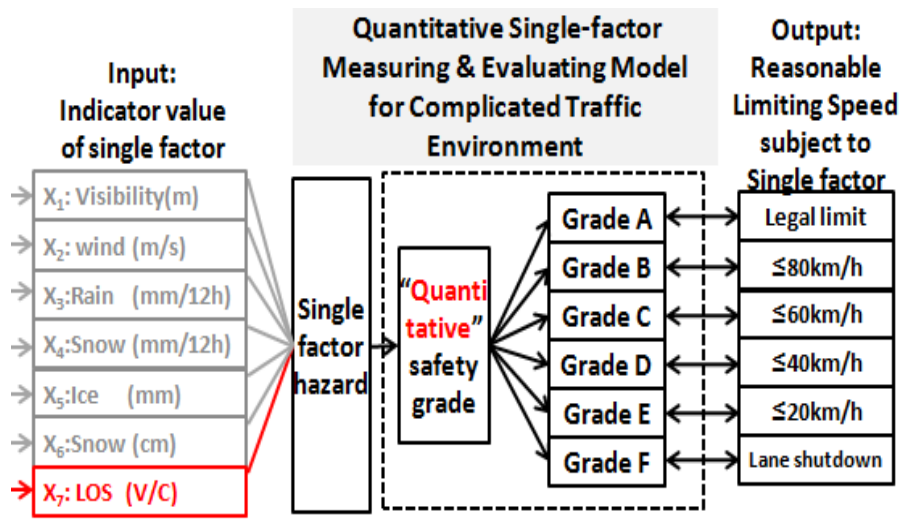

3-1-a "Quantitative Indicator $\mathrm{x}_{\mathrm{i}}$-Safety grades-Limiting Speeds" Modeling Design

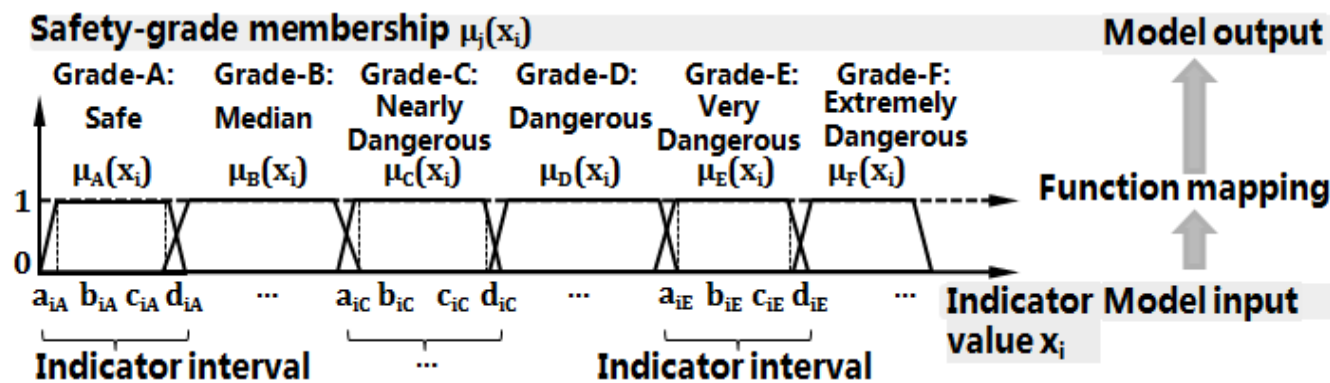

3-1-b Fuzzy Evaluation Membership Function $\mu_{\mathrm{j}}\left(\mathrm{x}_{\mathrm{i}}\right)$ of Single-factor $\mathrm{x}_{\mathrm{i}}(\mathrm{i}=1,2, \ldots, 7)$

Fig.3-1 Quantitative Single-factor Measuring \& Evaluating Model of Complicated Traffic Environment

"Fuzzy Evaluation"is selected as the method of single-factor measuring \& evaluation, with the trapezoid-shaped membership function $\mu_{\mathrm{j}}\left(\mathrm{x}_{\mathrm{i}}\right)$, where quantitative indicator $x_{i}$ as the independent variables, $\mu_{\mathrm{j}}\left(\mathrm{x}_{\mathrm{i}}\right)$ the membership degree of $\mathrm{x}_{\mathrm{i}}$ belonging to jth safety-grade as the dependent variables, Grade $\mathrm{j} \in\{\mathrm{A}$ (Safe), B (Median), C (Nearly Dangerous), D (Dangerous), E(Very Dangerous), $\mathrm{F}$ (Extremely Dangerous $)\}, \mu_{\mathrm{ij}}=\left(\mu_{\mathrm{iA}}\right.$, $\left.\mu_{\mathrm{iB}}, \mu_{\mathrm{iC}}, \mu_{\mathrm{iD}}, \mu_{\mathrm{iE}}, \mu_{\mathrm{iF}}\right)$ for short as Fig.3-1-b and Formula 3-1. The key is how to calibrate the boundary thresholds of $a_{i j}, b_{i j}, c_{i j}, d_{i j}$ (i.e. to partition the indicator's intervals).

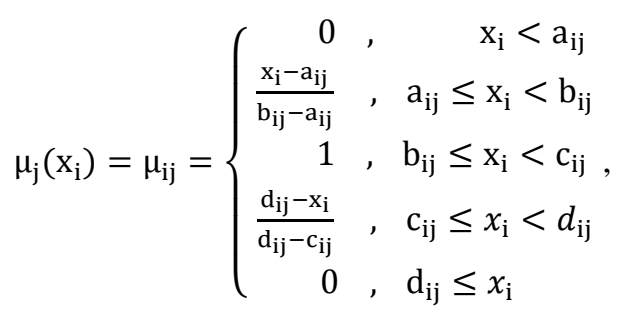

$\mathrm{j} \in\{\mathrm{A}, \mathrm{B}, \mathrm{C}, \mathrm{D}, \mathrm{E}, \mathrm{F}\}$

\subsection{Visibility Factor}

Vehicle's stopping sight distance (SSD) shall not exceed visible distance, therefore, the logical relation between limiting-speed (safety grade) and SSD and visible distance could be set as Fig.3-2.

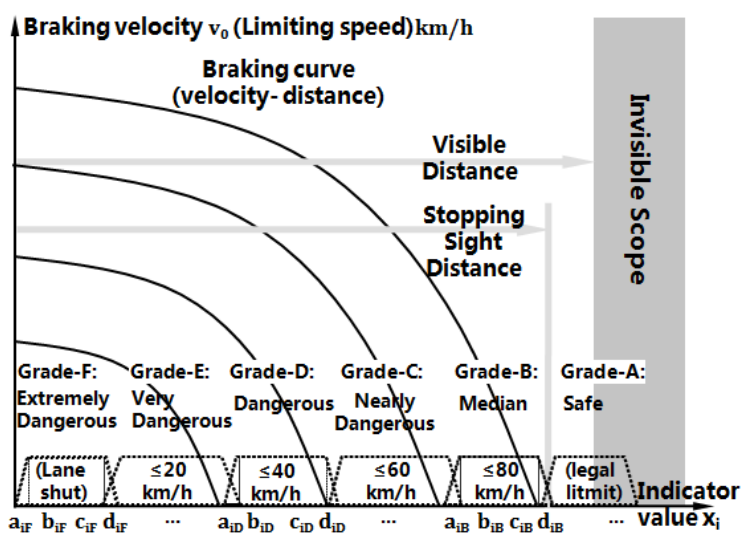

Fig.3-2 Relation of limiting-speed to visible distance

The 81st clause of the law[9] stipulates 3 graded limiting-speeds of 20/40/60 $\mathrm{kmph}$ subject to different visibility conditions. In view of the design speed of $80 / 100 / 120 \mathrm{~km} / \mathrm{h}$, it's necessary to supplement 2 grades of speed-limit " $\leq 80 \mathrm{~km} / \mathrm{h}$ " and "Lane-shutdown", with the former to guarantee traffic safety and the latter to enhance traffic efficiency. The calculating model of SSD ${ }^{[1 \sim 2]}$ (as Formula 3-2) could quantitatively indicate the mapping relation of 6 grades of limiting-speed 
(safety grade) to 6 intervals of visibility (visible distance) respectively, as Tab.3-1 and Fig.3-3.

$$
\mathrm{d}_{\mathrm{ss}}=\frac{\mathrm{v}_{0}}{3.6} \mathrm{t}_{\mathrm{r}}+\frac{\left(\frac{\mathrm{v}_{\mathrm{o}}}{3.6}\right)^{2}}{2 \mathrm{~g}(\mathrm{f}+\mathrm{i})}+\mathrm{d}_{\text {safe }}
$$

Where: $d_{s s}(m)$ the stopping sight distance, $\mathrm{v}_{\mathbf{0}}(\mathrm{km} / \mathrm{h})$ the Braking (initiative)velocity, $\mathrm{t}_{\mathbf{r}}(\mathrm{s})$ the Driver response time(assigned the norm value of $2.5 \mathrm{~s}[1 \sim 2,22]$ corresponding to free/steady flow condition), $d_{\text {safe }}$ equals $5 \sim 10(\mathrm{~m}), \mathrm{g}=9.8 \mathrm{~m} / \mathrm{s}^{2}$, f the longitudinal resistance coefficient between pavement(i.e. road surface) and tire to be assigned the downhill wet-pavement value of 0.25 according to technical standard [1,2] (Because of the inevitable correlation of visibility to wet weather elements including rain or snow), $i$ the longitudinal gradient (i>0 if uphill, $i<0$ if downhill) to be assigned the most dangerous value of $-3 \%$.

Tab.3-1 Mapping relation of Limiting-speed to visibility

\begin{tabular}{|c|c|c|c|}
\hline $\begin{array}{c}\text { Braking } \\
\text { speed } \\
\mathrm{km} / \mathrm{h}\end{array}$ & $\begin{array}{c}\text { Stopping } \\
\text { sight distance } \\
\mathrm{m}\end{array}$ & $\begin{array}{c}\text { Safe visible } \\
\text { distance } \\
\mathrm{m}\end{array}$ & $\begin{array}{c}\text { Indicator } \\
\text { interval } \\
\mathrm{m}\end{array}$ \\
\hline 5 & $3.92+5 \sim 10$ & 10 & $0-30$ \\
\hline 10 & $8.73+5 \sim 10$ & 20 & \\
\hline 20 & $21.05+5 \sim 10$ & 30 & $30-50$ \\
\hline 40 & $56.41+5 \sim 10$ & 50 & $50-100$ \\
\hline 60 & $106.09+5 \sim 10$ & 100 & $100-200$ \\
\hline 80 & $170.08+5 \sim 10$ & 200 & $200-260$ \\
\hline 90 & $207.44+5 \sim 10$ & 220 & \\
\hline 100 & $248.39+5 \sim 10$ & 260 & 260 L人日 \\
\hline
\end{tabular}

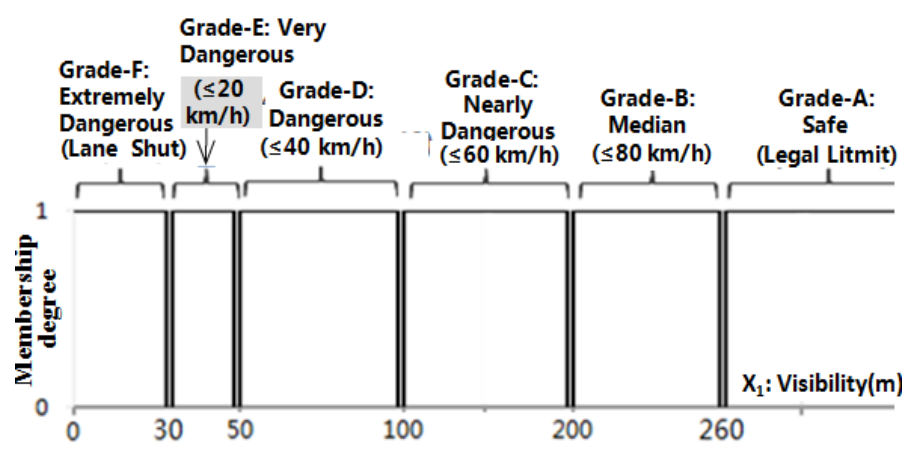

Fig.3-3 Fuzzy membership function $\mu_{1 j}$ of visibility $x_{1}$

\subsection{Windforce (Wind speed) Factor}

According to the traffic management measures against wind condition ${ }^{[11]}$ and the definition of wind grades[15], the fuzzy membership function mapping relation of limiting-speed (safety grade) to windforce (wind speed) could be obtained as Tab.3-2 and Fig.3-4.

Tab.3-2 Mapping relation of Limiting-speed to wind speed

\begin{tabular}{|c|c|c|c|c|c|}
\hline $\mathrm{x}_{\mathbf{i}}(\mathrm{m} / \mathrm{s})$ & {$[0,10.7)$} & {$[10.7,13.8)$} & {$[13.8,20.7$} & {$[20.7,28.4] \geq 28.4$} \\
\hline Safety-grade & A & B & C & D & F \\
\hline
\end{tabular}

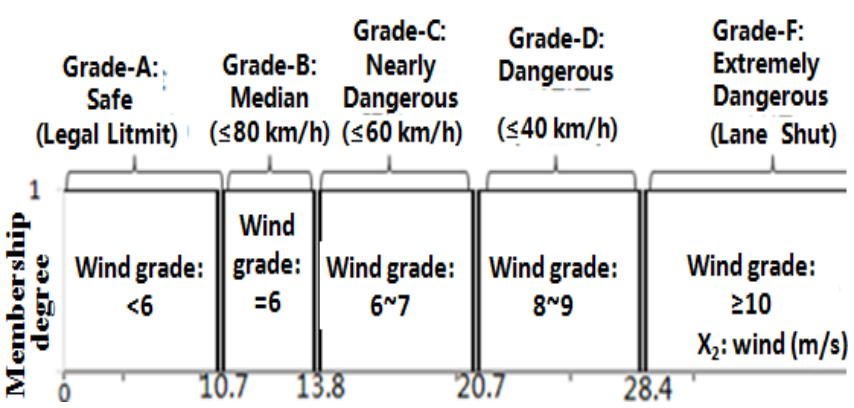

Fig.3-4 Fuzzy membership function $\mu_{2 j}$ of wind force(wind speed) $\mathrm{x}_{2}$

\subsection{Precipitation-related Factors}

\subsubsection{Rainfall Factor}

Railfall gives rise to water film on road surface, decreasing the resistance coefficient between pavement and tire, breaking vehicle's equilibrium between lateral resistance and centrifugal force, causing skid of vehicle. The calculating model of critical skidding-equilibrium of vehicle [1](as Formula 3-3), could answer the skid-avoiding limiting speeds.

$$
\mathrm{v}^{2} \leq 127 \mathrm{R}(\varphi+\varepsilon)
$$

Where: $R(m)$ the radius of vehicle turning path being smaller than road curvature in lane-changing or similar conditions(assigned to the value of $60 \mathrm{~m}$ on basis of the minimal turing radius $6 \sim 20 \mathrm{~m}$ of car/ truck, and the minimal curve radius of $30 \sim 38 \mathrm{~m}$ of highway intersection approach[13]); $\varepsilon$ the superelevation $=0$ representing the most dangerous horizontal pavement; as for $\varphi$ the lateral resistance coefficient between pavement and tire, literatures $[12,14]$ reveal the correlation between rainfall, water film thickness (WFT) and $\varphi$, as " The rainfall of $0.25 \mathrm{~mm} / \mathrm{h}$ could trigger WFT of $0.025 \sim 0.05 \mathrm{~mm}$ in cases ... cut $20 \% \sim 30 \%$ off $\varphi$ compared with the dry condition", with approximated/fitting equation is as Tab.3-3.

Tab.3-3 Approximated/Fit correlation between rainfall, WFT and $\varphi$

\begin{tabular}{|c|c|c|c|}
\hline $\begin{array}{c}\text { Rainfall } \\
(\mathrm{mm} / 12 \mathrm{~h})\end{array}$ & $\begin{array}{c}\text { Rainfall } \\
(\mathrm{mm} / \mathrm{h})\end{array}$ & $\begin{array}{c}\text { WFT } \\
(\mathrm{mm})\end{array}$ & $\varphi$ \\
\hline 1.52 & 0.12 & 0.0254 & 0.8 \\
\hline 3.04 & 0.25 & 0.0508 & 0.7 \\
\hline 7.62 & 0.64 & 0.1270 & 0.475 \\
\hline 15.24 & 1.27 & 0.2540 & 0.425 \\
\hline 22.86 & 1.90 & 0.3810 & 0.382 \\
\hline 30.48 & 2.54 & 0.5080 & 0.342 \\
\hline 38.10 & 3.18 & 0.6350 & 0.321 \\
\hline 45.72 & 3.81 & 0.7620 & 0.315 \\
\hline 53.34 & 4.44 & 0.8890 & 0.301 \\
\hline \multicolumn{4}{|c|}{ Fitting equation: $\varphi=-0.14 * \ln (\mathrm{WFT})+0.254$} \\
\hline
\end{tabular}

Embedding $\varphi$ into Formula 3-3, leads to the limiting-speeds s.t. different rainfall, as Tab.3-4: 
Tab.3-4 Mapping relation of Limiting-speed to rainfall

\begin{tabular}{|c|c|c|c|}
\hline Rainfall $(\mathrm{mm} / 12 \mathrm{~h})$ & $10 \pm 0.1$ & $70 \sim 100$ & $160 \sim 185$ \\
\hline$\varphi$ & $0.5 \pm 0.01$ & $0.2 \pm 0.01$ & $0.1 \pm 0.01$ \\
\hline Limiting speed $\mathrm{v}(\mathrm{km} / \mathrm{h})$ & 61.72 & 39.04 & 27.60 \\
\hline
\end{tabular}

In view of probable rainfall-observing time-lag deviation between practically observed indicator values during rain and final results after rain, it's necessary to combine the observed rainfall and forecasting one[16], expand the 3 intervals in Tab.3-4 to 4 intervals matching 4 grades of limiting-speeds, as Tab.3-5 and Fig.3-5.

Tab.3-5 Mapping relation of Limiting-speed to rainfall

\begin{tabular}{|c|c|c|c|c|}
\hline $\mathrm{x}_{\mathbf{i}}(\mathrm{mm} / 12 \mathrm{~h})$ & {$[0,5)$} & {$[5,70)$} & {$[50,140)$} & $\geq 125$ \\
\hline Safety grade & A & C & D & E \\
\hline
\end{tabular}

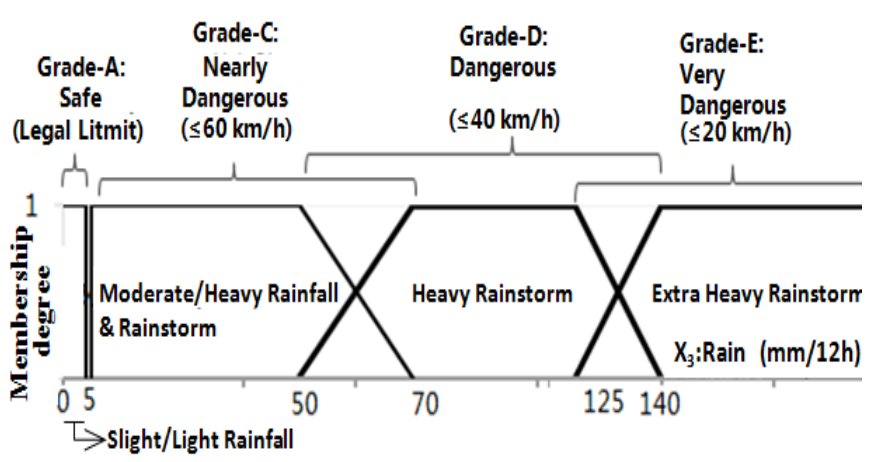

Fig.3-5 Fuzzy membership function $\mu_{3 j}$ of rainfall $x_{3}$

\subsubsection{Snowfall Factor}

Refering to the modeling logic of rainfall factor, based on the definition of snowfall grades[16], the indicator values of snowfall could be categorized into 4 intervals (i.e. "Slight/Light snowfall", "Moderate/Heavy snowfall", "Blizzard", "Heavy/Extra Heavy Blizzard") matching 4 grades of limiting-speed (safety grade), as Tab.3-6 and Fig.3-6.

Tab.3-6 Mapping relation of Limiting-speed to snowfall

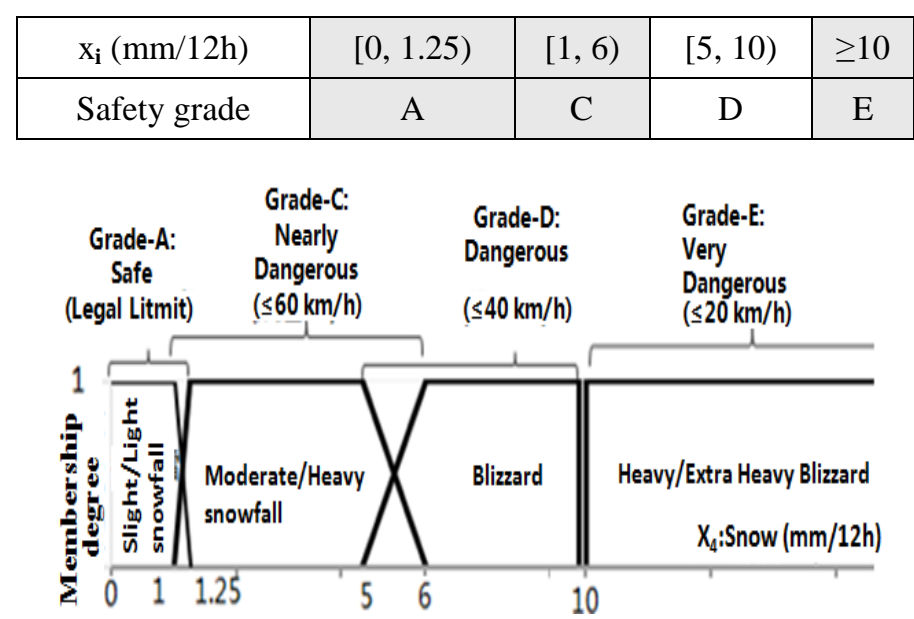

Fig.3-6 Fuzzy membership function $\mu_{4 j}$ of snowfall $x_{4}$

\subsubsection{Pavement Ice Thickness Factor}

Based on the correlation of pavement resistance coefficient to pavement icing structure ${ }^{[17]}$ and the test result ${ }^{[18]}$ " The pavement texture depth of $0.2 \sim 1(\mathrm{~mm})$ relate to pavement resistance coefficient of 0.6 0.2" and Formula 3-3, ice thickness could be categorized into 3 intervals matching 3 grades of limiting-speeds, with the modeling of fuzzy membership functions as Tab.3-7 and Fig.3-7.

Tab.3-7 Mapping relation of Limiting-speed to ice thickness

\begin{tabular}{|c|c|c|c|}
\hline $\mathrm{x}_{\mathbf{i}}(\mathrm{mm})$ & $\varphi$ & limiting-speed & Safety-grade \\
\hline $0.0<\mathrm{x}_{\mathbf{i}}<0.2$ & $0.30 \sim 0.35$ & $48 \sim 52(\mathrm{~km} / \mathrm{h})$ & $\mathrm{C}$ \\
\hline $0.2 \leq \mathrm{x}_{\mathbf{i}}<0.5$ & $0.15 \sim 0.25$ & $34 \sim 44(\mathrm{~km} / \mathrm{h})$ & $\mathrm{D}$ \\
\hline $\mathrm{x}_{\mathbf{i}} \geq 0.5$ & $0.05 \sim 0.10$ & $20 \sim 26(\mathrm{~km} / \mathrm{h})$ & $\mathrm{E}$ \\
\hline
\end{tabular}

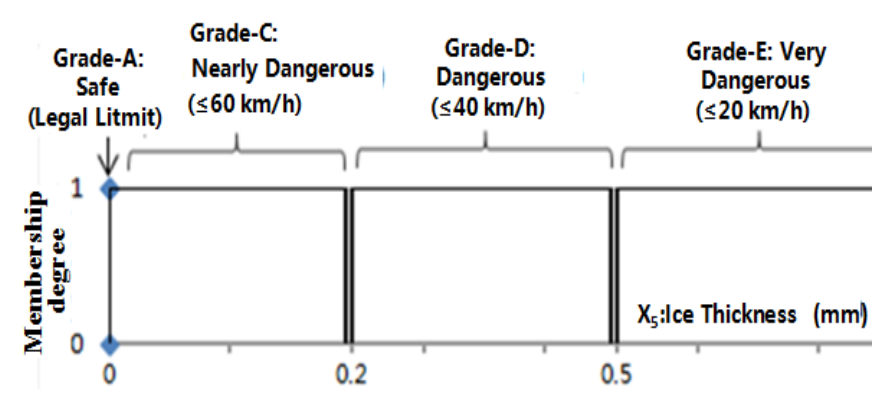

Fig.3-7 Fuzzy membership function $\mu_{5 j}$ ice thickness $x_{5}$

\subsubsection{Pavement Snow Thickness Factor}

Based on the correlation between pavement snow depth and vehicle spacing(stopping sight distance) distribution[17,19], snow thickness could be categorized into 3 intervals matching 3 grades of limiting-speeds, with the modeling of fuzzy membership functions as Tab.3-8 and Fig.3-8.

Tab.3-8 Mapping relation of Limiting-speed to snow thickness

\begin{tabular}{|c|c|c|c|}
\hline $\mathrm{x}_{\mathbf{i}}(\mathrm{cm})$ & $\begin{array}{c}\text { Safe } \\
\text { spacing }\end{array}$ & $\begin{array}{c}\text { Safe braking speed s.t. } \\
\text { stopping sight distance }\end{array}$ & $\begin{array}{c}\text { Safety } \\
\text { grade }\end{array}$ \\
\hline $0<\mathrm{x}_{\mathbf{i}}<2$ & $>80 \mathrm{~m}$ & $60(\mathrm{~km} / \mathrm{h})$ & $\mathrm{C}$ \\
\hline $2 \leq \mathrm{x}_{\mathbf{i}}<10$ & $80 \mathrm{~m}$ & $40 \sim 50(\mathrm{~km} / \mathrm{h})$ & $\mathrm{D}$ \\
\hline $\mathrm{x}_{\mathbf{i}} \geq 10$ & $20 \mathrm{~m}$ & $18 \sim 20(\mathrm{~km} / \mathrm{h})$ & $\mathrm{E}$ \\
\hline
\end{tabular}

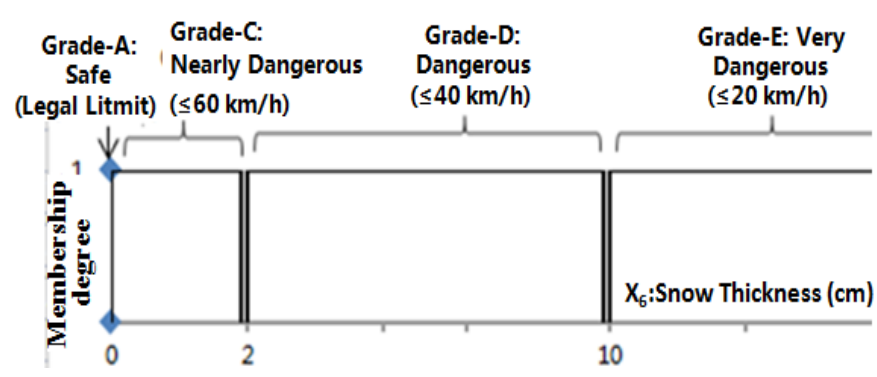

Fig.3-8 Fuzzy membership function $\mu_{6 j}$ of snow thickness $x_{6}$

\subsection{LOS (Ratio of V to C) Factor}

Technical standard[1] defines 4 grades of freeway's level-of-Service(LOS). The minimal vehiclespacing (corresponding to the maximal density) of 
LOS-I equivalently being the maximal vehicle stopping-sight-distance of LOS-II, constrain the maximal speed of LOS-II etc, hence, the logical relation between limiting-speed (safety grade), stopping sight distance and V/C ratio could be set as Fig.3-9. The calculating model of vehicle's stopping-sight- distance[1 2](as Formula 3-2) could quantitatively indicate mapping relation of 6 grades of limiting- speed (safety grade) i.e. " $0 / 20 / 40 / 60 / 80$ kmph / legal-limit" to 6 intervals of $\mathrm{V} / \mathrm{C}$ ratio(and time occupancy: o) respectively, with the fuzzy membership function as Tab.3-10 and Fig.3-10 $($ Design speed of freeway $=100 \mathrm{~km} / \mathrm{h})$.

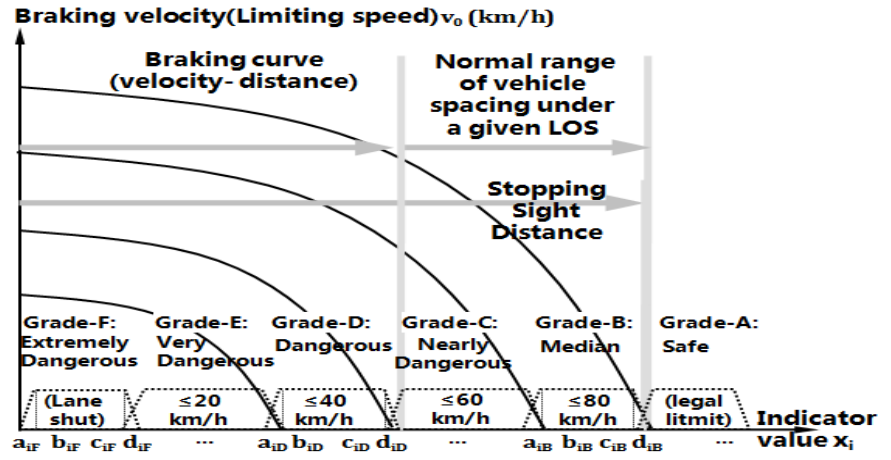

Fig.3-9 Relation of Limiting-speed to range of spacing

Tab.3-10 Mapping relation of Limiting-speed to V/C ratio(time occupancy)

\begin{tabular}{|c|c|c|c|c|c|c|}
\hline V/C Ratio $\mathrm{x}_{\mathbf{i}}(\mathrm{o})$ & {$[0,0.86)$} & {$[0.86,0.9)$} & {$[0.9,1)$} & $\mathrm{x}_{\mathbf{i}} \geq 1(\mathrm{o} \leq 0.66)$ & $\mathrm{x}_{\mathbf{i}} \geq 1(0.66<0 \leq 0.9)$ & $\mathrm{x}_{\mathbf{i}} \geq 1(0.9<0 \leq 1.0)$ \\
\hline Density (pcu/km/lane) & $\leq 25$ & $\leq 25$ & $\leq 45$ & $\leq 55$ & $>55$ & $>55$ \\
\hline Safety grade & A & B & C & D & E & F \\
\hline
\end{tabular}

Notes: $\mathrm{f}$ the longitudinal resistance coefficient between pavement and tire to be assigned the downhill dry-pavement value of 0.9 according to technical standard [1,2] (In view of NO inevitable correlation existing between LOS to wet weather elements), i the longitudinal gradient to be assigned the most dangerous value of $-3 \%, \mathrm{t}_{\mathbf{r}}(\mathrm{s})$ the Driver response time assigned the agile value of $1.0 \mathrm{~s}[20]$ corresponding to non-steady/forced flow condition), dessity calibration is based on vehicle size as the upper limit value of light passenger car and the lower limit value of heavy cargo truck[10].

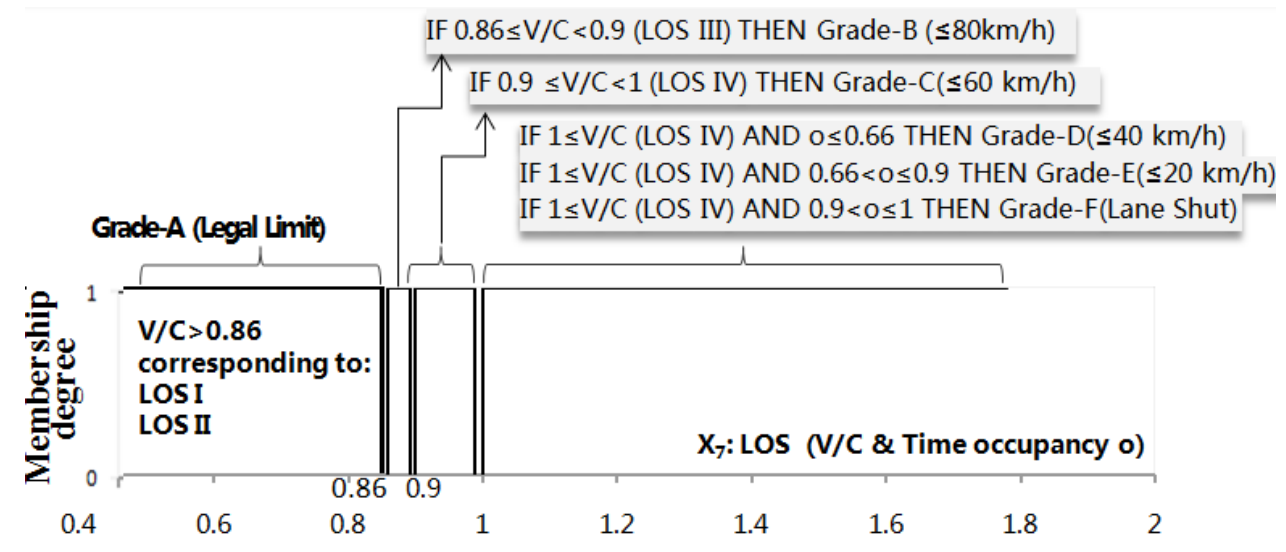

Fig.3-10 Fuzzy membership function $\mu_{7 j}$ of $\operatorname{LOS}\left(\mathrm{V} / \mathrm{C}\right.$ ratio) $\mathrm{x}_{7}$

\section{QUANTITATIVE MULTI-FACTOR} MEASURING \& EVALUATING MODEL OF COMPLICATED TRAFFIC ENVIRONMENT AND SPEED-LIMIT TACTICS

\subsection{Tactic for Measuring \& Evaluation}

The quantitative single-factor evaluation of ith factor outputs a 6-dimension membership-degree vector $\mu_{\mathrm{ij}}=\left(\mu_{\mathrm{iA}}, \mu_{\mathrm{iB}}, \mu_{\mathrm{iC}}, \mu_{\mathrm{iD}}, \mu_{\mathrm{iE}}, \mu_{\mathrm{iF}}\right)$, called "Single-factor safety grade", 7 factors output seven 6 vectors comprising multi-factor membershipdegree matrix $\left[\mu_{\mathrm{ij}}\right]=\left[\begin{array}{c}\mu_{1 \mathrm{j}} \\ \mu_{2 \mathrm{j}} \\ \ldots \\ \mu_{7 \mathrm{j}}\end{array}\right]=\left[\begin{array}{cccc}\mu_{1 \mathrm{~A}} & \mu_{1 \mathrm{~B}} & \ldots & \mu_{1 \mathrm{~F}} \\ \mu_{2 \mathrm{~A}} & \mu_{2 \mathrm{~B}} & \ldots & \mu_{2 \mathrm{~F}} \\ \ldots & \ldots & \ldots & \ldots \\ \mu_{7 \mathrm{~A}} & \mu_{7 \mathrm{~B}} & \ldots & \mu_{7 \mathrm{~F}}\end{array}\right]$. The core of comprehensive quantitative multi-factor evaluation, is to assign 7 weights to 7 factors respectively, multiplying $\left[\mu_{\mathrm{ij}}\right]$ by 7 weights, so as to incorporate 7 "Single-factor safety grade" into a "Multi-factor safety grade" $\mu_{\mathrm{j}}=\left(\mu_{\mathrm{A}}, \mu_{\mathrm{B}}, \mu_{\mathrm{C}}, \mu_{\mathrm{D}}, \mu_{\mathrm{E}}\right.$, $\mu_{\mathrm{F}}$ ), as Fig.4-1 and Formula 4-1. In condition of free-flow without rain/snow/wind, fog will push visibility factor's safety grade closer to "grade-F: Dxtremely Dangerous" than any other factor's.

Employing "Wooden Cask Effect Theory", visibility factor turns into the "Shortest Board" among 7 factors. The weight-assigning strategy of this paper is that the weight of shortest board factor(s) SHALL be 1 and the others be 0, i.e. multi-factor safe-grade equals the shortest board(s)'s. 


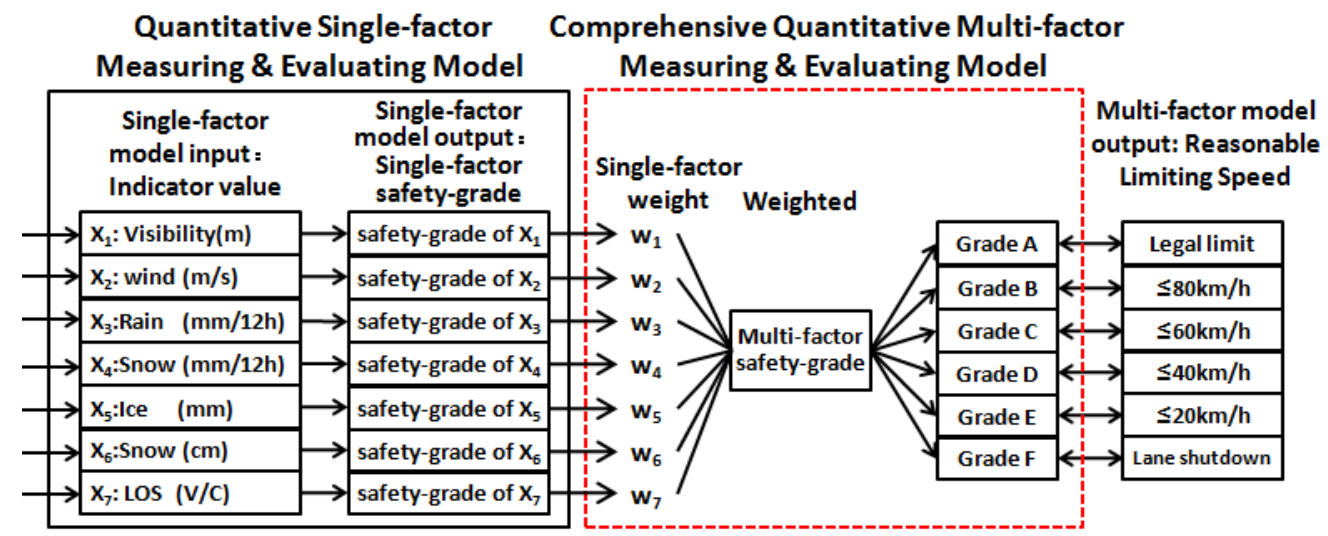

Fig.4-1 Comprehensive quantitative multi-factor measuring \& evaluating model

$$
\mu_{j}=\left(w_{1}, w_{2}, \ldots, w_{7}\right) *\left[\begin{array}{cccc}
\mu_{1 \mathrm{~A}} & \mu_{1 \mathrm{~B}} & \ldots & \mu_{1 \mathrm{~F}} \\
\mu_{2 \mathrm{~A}} & \mu_{2 \mathrm{~B}} & \ldots & \mu_{2 \mathrm{~F}} \\
\ldots & \ldots & \ldots & \ldots \\
\mu_{7 \mathrm{~A}} & \mu_{7 \mathrm{~B}} & \ldots & \mu_{7 \mathrm{~F}}
\end{array}\right]
$$$$
=\left(\mu_{\mathrm{A}}, \mu_{\mathrm{B}}, \mu_{\mathrm{C}}, \mu_{\mathrm{D}}, \mu_{\mathrm{E}}, \mu_{\mathrm{F}}\right)
$$

Thus, the key to weight-assigning is how to identify the shortest board factor(s)'s safety-grade. Since the membership degrees of rainfall and snowfall might be either decimals (representing fuzzy safety-grade) or integer (0 or 1, representing deterministic safety-grade), whereas the membership degrees of all other factors are just integers, therefore the method of weight-assigning is classified into 2 categories, contingent on whether shortest board(s)'s safety-grade is deterministic or not, comprise the comprehensive quantitative multi-factor measuring \& evaluating model.

\subsection{Method for Measuring \& Evaluation}

\subsubsection{Situation of shortest-board being a member of deterministic grade (Membership degree $=0$ or 1)}

For example,

$\left[\begin{array}{cccc}\mu_{1 \mathrm{~A}} & \mu_{1 \mathrm{~B}} & \cdots & \mu_{1 \mathrm{~F}} \\ \mu_{2 \mathrm{~A}} & \mu_{2 \mathrm{~B}} & \cdots & \mu_{2 \mathrm{~F}} \\ \cdots & \cdots & \cdots & \cdots \\ \mu_{7 \mathrm{~A}} & \mu_{7 \mathrm{~B}} & \cdots & \mu_{7 \mathrm{~F}}\end{array}\right]=\left[\begin{array}{cccccc}0 & 0 & 1 & 0 & 0 & 0 \\ 0 & 0 & 0 & 1 & 0 & 0 \\ 0 & 0 & 0.9 & 0.1 & 0 & 0 \\ 0 & 0 & 0.2 & 0.8 & 0 & 0 \\ 0 & 0 & 1 & 0 & 0 & 0 \\ 1 & 0 & 0 & 0 & 0 & 0 \\ 0 & 0 & 1 & 0 & 0 & 0\end{array}\right]$,

shortest-board factor of visibility $\mathrm{x}_{2}$ could be identified directly with its single-factor safety grade $=\mathrm{D}$ (Dangerous). Assigning the weight of 1 to visibility factor, Grade-D-matching limiting-speed of " $\leq 40 \mathrm{~km} / \mathrm{h}$ " could be deduced.

\subsubsection{Situation of shortest-board being a member of fuzzy grade $(0<$ Membership degree $<1)$}

When and only when rainfall $\mathrm{x}_{3}$ and snowfall $\mathrm{x}_{4}$ act as or probably act as shortest-boards simultaneously, moreover both of $\mathrm{x}_{3}$ and $\mathrm{x}_{4}$ belong to a fuzzy safety-grade, i.e. $0<\mu_{3 j}<1$ and $0<\mu_{4 \mathrm{j}}<1$ (j=C or D), for example $\left[\begin{array}{cccccc}0 & 1 & 0 & 0 & 0 & 0 \\ 1 & 0 & 0 & 0 & 0 & 0 \\ 0 & 0 & 0.9 & 0.1 & 0 & 0 \\ 0 & 0 & 0.2 & 0.8 & 0 & 0 \\ 0 & 0 & 1 & 0 & 0 & 0 \\ 1 & 0 & 0 & 0 & 0 & 0 \\ 0 & 0 & 1 & 0 & 0 & 0\end{array}\right]$,

the shortest-board factor and its sinle-factor safetygrade could NOT be identified directly $\left(\mathrm{x}_{3} \rightarrow \mathrm{C} /\right.$ $\mathrm{x}_{4} \rightarrow \mathrm{D}$ ?). "Entropy Weighted Method" could be applied to: (1)Calculates the entropies of rainfall $x_{3}$ and snowfall $\mathrm{x}_{4}$ respectively using formula of $\mathrm{e}_{\mathrm{i}}=$ $-\sum_{\mathrm{j}=\mathrm{A}}^{\mathrm{F}} \mu_{\mathrm{ij}} * \ln \left(\mu_{\mathrm{ij}}\right), \quad \mathrm{e}_{3}=0.32$ and $\mathrm{e}_{4}=0.50$;

Entropy weithts $\mathrm{w}_{\mathrm{i}}=1-\mathrm{e}_{\mathrm{i}}(\mathrm{i}=3,4)$ normalized as $\mathrm{w}_{3}^{* *}$

$$
\begin{aligned}
& =0.58 \quad \text { and } \\
& \left(\mathrm{w}_{3}^{* *}, \mathrm{w}_{4}^{* *}\right)^{*}\left[\begin{array}{llll}
\mu_{3 \mathrm{~A}} & \mu_{3 \mathrm{~B}} & \ldots & \mathrm{w}_{3 \mathrm{~F}}^{* *} \\
\mu_{4 \mathrm{~A}} & \mu_{4 \mathrm{~B}} & \ldots & \mu_{4 \mathrm{~F}}
\end{array}\right]=0.42 ;
\end{aligned}
$$

obtain dual-fator membership degree of $\boldsymbol{\mu}_{\mathrm{C}}=0.606 /$ $\boldsymbol{\mu}_{\mathrm{D}}=0.394$, which converts 2 fuzzy safety-grades into 1 deterministic one, so dimension-reducting membership degree matrix $=\left[\begin{array}{cccccc}0 & 1 & 0 & 0 & 0 & 0 \\ 1 & 0 & 0 & 0 & 0 & 0 \\ 0 & 0 & 0.606 & 0.394 & 0 & 0 \\ 0 & 0 & 0.606 & 0.394 & 0 & 0 \\ 0 & 0 & 1 & 0 & 0 & 0 \\ 1 & 0 & 0 & 0 & 0 & 0 \\ 0 & 0 & 1 & 0 & 0 & 0\end{array}\right]$; (4) Identifing the shortest- board factor(s) for the second time, which are rainfall $\mathrm{x}_{3}$, snowfall $\mathrm{x}_{4}$, ice thickness $\mathrm{x}_{5}$, LOS (V/C Ratio) $\mathrm{x}_{7}$, assigning the weight(s) of 1 to the 4 factors (normalized $\left.\mathrm{w}_{3}^{* *}=\mathrm{w}_{4}^{* *}=\mathrm{w}_{5}^{* *}=\mathrm{w}_{7}^{* *}=1 / 4=0.25\right)$, safety grade-C matching the limiting-speed of " $\leq 60 \mathrm{~km} / \mathrm{h}$ " could finally be obtained.

\section{CONCLUSION}

The comprehensive quantitative measuring models for complicated traffic environment of freeway proposed by this paper, elaborate the rationale for variable speed-limit of freeway, theoretically and technologically support the R\&D of relevant control system, with features as follows: (1) Comprehensiveness of the multi-factor model, embracing multiple factors of complicated traffic environment, also emphasizing the distinctive impact of shortest 
-board factor(s), guarantees the reasonability and feasibility of the comprehensive outcome; (2) Quantitativeness of the single-factor/multi-factor models, produces the matching rules of reasonable limiting-speed subject to each and every factor, guarantees the maneuverability for the variable speed-limit of freeway.

\section{ACKNOWLEDGEMENT}

Sponsored by 12th 5-year plan National Key Technology R\&D Program "Key Technologies and System Integration of Network-based Coordinated Control of Freeway Traffic Safety (2014BAG01B04)", Key Laboratory of Road Traffic Safety of Ministry of Public Security.

\section{REFERENCES}

[1] Ministry of Transport of China 2006. Design Specification of Highway Route: JTG D20-2006 [Standard]. Beijing: People's Communication Publishing House.

[2] Ministry of Transport of China 2004. Technical Standard of Highway Engineering: JTG B01-2003 [Standard]. Beijing: People's Communication Publishing House.

[3] Ministry of Public Security of China 2011. Specification for Highway Traffic Safety Status Evaluation: GAT 960-2011 [Standard]. Beijing: Standards Press of China.

[4] Research Institute of Highway Ministry of Transport of China, National Meteorological Center, Key Laboratory of ITS Technologies of Transport Industry 2014. Rating of pre-warning of highway traffic condition under snowy and icy weather conditions [Standard]. To be published.

[5] PEI Yu Long, CHENG Guo Zhu, DAI Lei Lei, etc 2008. Discussion on Highway Speed Limit. UrbanTransport of China 6(2): 23-28.

[6] JIANG Hong, LI Feng 2012. Modeling of Stopping Sight Distance and Analysis of Safe Speed on Freeway with Different Road Conditions. Journal of xi'an Technology Univ. 32(1): 25-30.

[7] Thawat Watanatada, Clell G. Harral, William D. 0. Paterson, Ashok M. Dhareshwar, Anil Bhandari, Koji Tsunokawa, etc 1987. The World Bank Publication Highway Design Maintenance standards series 995 vol.1: Highway Design Maintenance standards model vol.1: Description of the HDM-III Model. Baltimore and London: The Johns Hopkins University Press.

[8] American Association of State Highway and Transportation Officials (AASHTO), Federal Highway
Administration (FHWA), Transportation Research Board (TRB) 2006. Highway Safety Manual. AASHTO Subcommittee on Design.

[9] The state council of China 2004. Regulation on the Implementation of the Road Traffic Safety Law of China[Law].

[10] Ministry of Public Security of China 2008. Power-driven Vehicle-Types, Terms and Definitions: GA802-2008[Standard]. Beijing: Standards Press of China.

[11] Public Security Department of Jiangsu Province, Transport Department of Jiangsu Province, Transport Holdings Ltd. of Jiangsu Province 2009. Specification on Freeway Traffic Management under severe weather circumstance [Standard]. Nanjing: People's government of Jiangsu Province.

[12] Department of Transportation, Federal Highway Administration (FHWA), Transportation Research Board (TRB) 2012. Guideline for Disseminating Road Weather Advisory or Control Info. FHWA- JPO-12-046. Springfield, VA: The National Technical Information Service.

[13] Ministry of Housing and Urban-Rural Development of China 1991. Design Specification of Urban Street: CJJ37-2012 [Standard]. Beijing: China Building Industry Press.

[14] Applied Research Associates Inc. Champaign IL, CDRM Inc. State College PA, NASA Langley Research Center Hampton VA, Pennsylvania Transportation Institute University Park PA 2011. Guide for Pavement Friction. NCHRP No.01-43 Report in 2009.02, NCHRP web-only document No. 108 in 2011.04. Transportation Research Board, National Research Council, US.

[15] General Administration of Quality Supervision, Inspection and Quarantine of China, Standardization Administration of China 2012. Wind Scale: GB/T 285912012 [Standard]. Beijing: Standards Press of China.

[16] General Administration of Quality Supervision, Inspection and Quarantine of China, Standardization Administration of China 2012. Grade of Precipitation: GB/T 28592-2012 [Standard]. Beijing: Standards Press of China.

[17] PEI Yu Long, FU Chuan Yun 2012. Traffic Operation Safety Evaluation of Icy \& Snowy Urban Street. 11st National Academic Conference Proceedings on Urban Traffic 2012: 30-34.

[18] HONG Dan, YU Wen Ke 2010. Effect of Anti-sliding on Rough Pavement Under the Condition of Ice. Traffic Technology and Economy (58):86-88.

[19] LUO Li Jun, GAO Han, PEI Yu Long 1999. Minimal Safe Vehicle Spacing under icy condition. Heilongjiang Traffic Technology (1):33-34.

[20] WANG Dian Hai 2002. Traffic Flow Theory. Beijing: People's Communication Publishing House. 